\title{
NO PAIN, NO GAIN: INSIGHTS INTO CHANGING INDIVIDUAL VOLITIONAL BEHAVIOUR
}

\begin{abstract}
Physical activity is an important component of a healthy lifestyle. The purpose of this study is three-fold: first, to empirically examine the effect of attitudes on people's intentions toward starting a new physical activity in three weight groups; second, to explore differences within various demographic groups and finally, to offer research and practical implications for social marketers who are working in the area of physical activity. A total of 1,459 respondents participated in an online survey. Our findings indicate that when individuals hold both negative and positive attitudes toward physical activity, they will have higher intentions to start a new physical activity. Empirical examination identified that overweight and obese people have more negative and less positive attitudes than healthier people toward physical activity. The results indicate that overcoming negative attitudes and reinforcing positive attitudes remains as a necessary condition to influence volitional behaviours such as physical activity, which requires cognitive processing and actions in order for behaviour to be changed. People engaging in physical activities understand both positive and negative effects of physical activities, and they may engage in physical activities despite knowing there are short term costs.
\end{abstract}

Keywords: Physical activity, social marketing, theory of planned behaviour 


\section{Introduction}

Participation in various physical activities has been found to be a core component of maintaining a healthy lifestyle (Hamilton \& White, 2008). Decades of studies show that physical exercise is associated with various health benefits such as increased strength and flexibility, reduced cardiovascular disease risk, reduced stress and lower depression rates (Aarts et al., 1997; Blair et al., 2001; Sallis \& Patrick, 1994). Despite its importance, studies show that only $8 \%$ of adolescents in the United States engage in the recommended level of physical activity, and physical activity rates tend to decline with age (Troiani et al., 2008). In Australia, a similar trend has been found in the general population, for example, the proportion of people who exercised at moderate levels also decreased, from $24 \%$ in 2001 to $22 \%$ in 2008. Consistent with the above data, in Australia, the proportion of people who were sedentary increased from 31\% to 35\% for men and 32\% to 36\% for women (ABS, 2011). The majority of the adult population in general is either sedentary or not sufficiently active (Dishman \& Buckworth, 2001; Sniehotta et at., 2005). Consequently, programs designed to help motivate people to be physically active and maintain physical activity are important. It has been shown that physical activity involvement is also related to a healthy lifestyle pattern (Vidmar, 1992). For example, active individuals are less likely to smoke cigarettes (Aaron et al., 1995), and younger individuals are likely to exhibit better academic performance (Dwyer et al., 1996; Shephard, 1996).

Various research has been applying theoretical models to predict which individuals are, or will be, active or inactive at a given point in time (Courneya et al., 1998; Courneya, 1995; Mummery et al., 2000). One of the widely used theories to understand people's motivation to undertake physical activity is Ajzen's Theory of Planned Behaviour (TPB) (see Luca \& Suggs, 2013). Nonetheless, studies on the impact of attitude toward intention have produced mixed results (Lowe et al., 2002) suggesting ongoing research attention is warranted to 
understand behaviours that have a volitional component, such as physical activity. Research shows that the characteristic attributed to 'attitude' is evaluative in nature (i.e. weighting up the pros and cons, including planning actions - short-term and long-term) (Fishbein \& Ajzen, 1975). Attitude is an individual's disposition to respond favourably or unfavourably toward an object, person or event (Ajzen, 1989). Thus, four attitudes (i.e. negative, positive, instrumental and affective) will be explored in this study. Further, Courneya et al.'s (1999) work suggests that studies on TPB often overlook the influence of demographic characteristics such as age, gender, income and education as moderating factors. Given that physical activity participation rates vary with demographic factors such as age, this is an important omission (Cerin \& Leslie, 2008; Giles-Corti \& Donovan, 2002; Lindstrom et al., 2001; McAuley et al., 2003; Talbot et al., 2000). Thus, the purpose of this study is three-fold: first, to explore the effect of attitudes on people's intentions toward starting a new physical activity; second, to explore differences in behaviours within various demographic groups that are known to be associated with physical activity and finally, to offer research and practical implications for social marketers who are working in the area of physical activity.

\section{Literature review}

Numerous psychological models have been applied to health-related behaviour (Conner and Norman, 1996), but the most widely used is the Theory of Planned Behaviour (TPB). TPB has been successful in understanding a wide range of social issues (Holdershaw et al., 2003; Parkinson et al., 2012; Smith \& Paladino, 2010) and predicting health-related behaviours, including physical activity (Armitage \& Connor, 2001; Conner \& Sparks, 2005; Godin \& Kok, 1996).

Behavioral intentions are considered to be a key ingredient in many health behaviour models (Abraham \& Sheeran, 2000; Armitage \& Conner, 2000; Wallston \& Armstrong, 2002; 
Weinstein, 2003; Sniehotta et al., 2005) including the Theory of Reasoned Action, the Theory of Planned Behaviour (TPB) and the Health Belief Model. TPB, a widely used theory in social marketing, posits that attitude together with social norms and perceived behavioural control will shape individual's behavioural intentions and ultimately, their consequent actions (Ajzen, 1991; Ajzen \& Fisbhein, 1980). TPB suggests that an individual’s intention to perform a behaviour is a key determinant of that behaviour because it accounts for particular motivational factors such as how hard an individual is willing to try (effort to be exerted to perform the behaviour) (Courneya et al., 1999). TPB has been used for predicting exercising intention and behaviour among adolescents (Mummery et al. 2000; Hamilton \& White, 2008), adults (Godin, 1993; Lowe et al., 2002), and older persons (Courneya et al., 1998); and mediating the relationship between personality and exercise behaviour (Courneya et al., 1999). Overall, there is a strong support demonstrated for the robustness of TPB in explaining intention to exercise and to perform subsequent behaviour (Hamilton \& White, 2008).

The attitude toward behaviour, either positive or negative, is a function of the beliefs concerning the perceived consequences of performing a specific action and a personal evaluation of each of those consequences (Godin, 1993). An individual who holds strong beliefs that positively valued outcomes will result from performing the behaviour (e.g. physical exercise) will have a positive attitude toward the behaviour. On the contrary, an individual who holds strong belief that negatively valued outcomes will result from the behaviour will have a negative attitude (Ajzen \& Fisbhein, 1980; Montano \& Kasprzyk, 2008). 


\section{Hypotheses development}

Based on the previously discussed theoretical and empirical literature, the study proposes several hypotheses which explore the impact of attitudes (i.e. negative, positive, instrumental and affective) on individuals’ intention to start a new physical activity.

Studies on the intention-behaviour relationship have shown a gap between intention and behaviour can mainly be attributed to a person who intends to act, but who does not follow through (Orbell \& Sheeran, 1998; Sniehotta et al., 2005). Thus, it can be assumed that intentions play an important role in health behaviour change because those without intentions are rarely found to be engaged in action (Sniehotta et al., 2005). Moreover, an individual tends to simultaneously evaluate the positive and negative outcomes of those activities. For example, a person may believe that regular exercise will help him/her cope with stress but at the same time also would make them tired and sore. Each individual evaluates the consequences attached to each of their beliefs (Godin, 1993). Nonetheless, some attitudes will have a stronger influence than others. Studies show that negative (Nelson et al. 2009) and positive attitudes (Deforche et al., 2006; Mummery et al., 2000; Storch et al., 2007). toward physical activity each have an effect on physical activity Overweight and obese individuals tend to have a less positive attitude toward physical activities. Thus, we propose the following hypotheses:

Hypothesis 1: Negative attitudes toward physical activity are negatively related with individual's intention to start a new physical activity for individuals who are: (a) healthy-weight; (b) overweight; and (c) obese.

Hypothesis 2: Positive attitudes toward physical activity are positively related with individual's intention to start a new physical activity for individuals who are: (a) healthy-weight; (b) overweight; and (c) obese. 
One reason for the importance of attitudes to exercise in the prediction of behavioural intentions might be the instrumental and affective nature of exercise itself (Lowe et al., 2002). Studies show that the attitude component of an intention comprises both instrumental and affective beliefs. Instrumental beliefs relate to the benefits and costs associated with behaviour (e.g. harmful or beneficial, bad or good, worthless or valuable). This is in contrast to affective beliefs. Affective evaluations are emotion-laden judgments about the consequences of the behaviour (e.g. pleasant or unpleasant, enjoyable or unenjoyable) (Ajzen, 1991; Lowe et al., 2002). Research indicates that instrumental and affective beliefs play an important role in volitional exercise behaviour motivation such as intention to go jogging and hiking (Valois et al., 1988; Godin, 1987). Godin (1987) also found that affective evaluations significantly influenced exercise intention among pregnant women. Attitudes will influence people's behaviours with outcomes that are believed to be both beneficial and pleasant (Ajzen \& Driver, 1992). However, the immediate physical consequences of exercise are often negative ranging from soreness, fatigue and minor discomfort to severe distress, depending on the intensity of the behaviour (Lowe et al., 2006). Despite its negative consequences, studies found instrumental and affective attitude was positively associated with physical activities (Ajzen \& Driver, 1992) and maintenance of physical activities. Attitudes will be most favourable toward behaviour with outcomes that are believed to be both beneficial (instrumental) and pleasant (Lowe et al. 2002). Hence, we propose the following hypotheses:

Hypothesis 3: Positive instrumental attitudes toward physical activity are positively related with individual's intention to start a new physical activity for individuals who are: (a) healthy-weight; (b) overweight; and (c) obese.

Hypothesis 4: Positive affective attitudes toward physical activity are positively related with individual's intention to start a new physical activity for individuals who are: (a) healthy-weight; (b) overweight; and (c) obese. 


\section{Method}

Potential participants' contact details were obtained from a purchased list of persons who had previously opted to be contacted for marketing and market research purposes. The population for the current study was comprised of 106,828 people who resided within $20 \mathrm{~km}$ of the Melbourne Central Business District (CBD), Australia. Participants were aged 18 and over. Once ethical clearance was obtained from the Human Ethics Research Committee (MKT/05/13/HREC) at (institution withheld to preserve author anonymity), an email invitation containing a link to the online survey was sent by PostConnect, a division of Australia Post, to each potential participant. Of the 8,033 respondents who opened the email, a total of $25.18 \%(2,033)$ clicked the survey link. A total of 1,459 respondents participated in the online survey. Overall, there were 1,413 valid survey responses. The demographic profile of respondents is shown in Table 4. Participation in the online survey was voluntary and anonymous. Quantitative analysis was undertaken using IBM SPSS v. 21. Data cleaning was used to remove incomplete surveys, respondents who were under the age of 18 and those who did not reside within $20 \mathrm{~km}$ of the Melbourne CBD.

Intention toward starting any new physical activity in the coming twelve months was measured by a three-item scale adapted from Fishbein and Ajzen (1975) (e.g. I intend to start a new physical activity) using a Likert measure ranging from -3 (strongly disagree) to 3 (strongly agree). Following the Exercise, Recreation and Sport Survey published by the Australian Sports Commission (2010) physical activity was defined in our survey as any activity for exercise, recreation or sport. Negative (e.g. ...it would be painful) and positive attitudes (e.g. ...it would help me cope with stress) toward physical activities were measured by scale items developed by Nelson et al. (2010) using a Likert scale anchored from 1 (strongly disagree) to 5 (strongly agree). The conceptualisation of attitudes toward physical activities assesses both perception of the immediate experience and consequences of physical 
activity (Nelson et al., 2010). Finally, instrumental and affective attitude scales were based on those used by Conner and Sparks (1996). The anchors (-3 to 3) for the instrumental component were harmful/beneficial, bad/good and worthless/valuable, whereas the anchors for the affective attitude were unpleasant/pleasant, unenjoyable/enjoyable. The scores (i.e. -3 to +3 ) captured the psychology of double negatives, where a belief that a behaviour will not result in a negative outcomes contributes positively to the person's attitude (Furr, 2011). Finally, the Cronbach's alpha for all items are as follows: negative attitudes (8 items, $\alpha=$ .866 ); positive attitudes (6 items; $\alpha=.768$ ); instrumental attitudes ( 3 items; $\alpha=.898$ ); affective attitudes ( 2 items; $\alpha=.889$ ); and intentions ( 3 items; $\alpha=.960$ ), all exceeding recommended thresholds. Table 1 details the scale items used in this study.

Insert Table 1 About Here

\section{Results and discussion}

Multicollinearity diagnostic analysis was conducted to examine correlations between the independent variables. The results show that the variance inflation factors (VIF) scores are around 1 and lower than 5 which is indicative of minimal effect and multicollinearity not being problematic (Hair et al., 1998). Subsequently, separate linear multiple regression analyses (enter mode) were employed to test the hypotheses. 'Negative attitudes', 'positive attitudes', instrumental attitudes' and' affective attitudes' scales were the independent variables and 'intention to start a new physical activity' was the dependent variable. The respondents were divided into three categories based on their BMI level (i.e. healthy-weight, overweight, and obese). Table 2 shows the correlation matrix for the independent and dependent variables for each category. Overall, it shows that negative attitudes are negatively 
related to positive, instrumental and affective attitudes but not significantly related to the intention to start a new physical activity. Despite insignificant results, negative attitude is positively related to intention (for individuals who are healthy-weight) and negatively related to intention (for individuals who are overweight and obese). Furthermore, positive attitudes are positively related to instrumental and affective attitudes including the intention to start a new physical activity.

Subsequently, based on each category (i.e. healthy-weight, overweight, and obese), we conducted regression analyses, ANOVA and post-hoc analyses (Tukey HSD) to examine differences within the demographic profiles (i.e. BMI, gender, age, income and education).

Table 3 shows that the model had an adjusted $\mathrm{R}^{2}$ value of 0.128 (healthy-weight); 0.179 (overweight) and 0.119 (obese). Given the multitude of factors known to impact obesity (for example see http://www.shiftn.com/obesity/Full-Map.html for a complex systems map of obesity influences) the $\mathrm{R}^{2}$ values reported in the current study would be in line with reasonable expectations. Obesogenic factors extend considerably beyond the individual and many are not able to be captured through cognitive processing. Contrary to our prediction, negative attitudes toward starting a new physical activity is positively related to individuals' intentions to start a new physical activity for individuals who are healthy-weight $(\beta=0.145, p$ $<0.05$ ) and overweight $(\beta=0.151, p<0.05)$, but not for individuals who are obese. Thus, $\mathrm{H}_{1 \mathrm{a}}$ and $\mathrm{H}_{1 \mathrm{~b}}$ are not supported due to its opposite direction and $\mathrm{H}_{1 \mathrm{c}}$ is also not supported. In the correlation table (Table 3), the result shows that negative attitude is uncorrelated to intention to start a new physical activity for individuals who are obese. Nonetheless, the regression results show that negative attitudes toward physical activity have a positive impact on individuals' intentions to start a new physical activity in the next 12 months following the survey. This may indicate the case of a suppressor variable. Conger (1974, p. 36-37) defined a suppressor variable as “... a variable which increases the predictive validity of another 
variable (or set of variables) by its inclusion in a regression equation in multi-variate testing”. This is a variable that can raise the total the variance explained even though it has an insignificant correlation with the dependent variable in bi-variate testing and a strong correlation with other predictor variables in bi-variate explorations (Hinkle et al. 1994; Pedhazur, 1982; Woolley, 1997). Therefore, negative attitude may be acting as a suppressor variable. Despite insignificant correlations with intention, when combined with other variables, negative attitude has a positive impact toward intention to start a new physical activity for individuals classified as healthy-weight and overweight. The research implication is that in order to increase people's intention to start a new physical activity, people need to understand not only the potential benefits of physical activities but also the negative consequences such as soreness and pain. In this case, understanding the more complicated interplay between attitudinal variables is needed to determine how to effect change (Wolley, 1997).

Moreover, as predicted, results reveal that positive attitudes toward physical activity are positively related to individuals' intentions to start a new physical activity for individuals who are healthy-weight $(\beta=0.373, p<0.001)$; overweight $(\beta=0.455, p<0.001)$; and obese $(\beta=$ 0.375, $p<0.001)$. Hence, $\mathrm{H}_{2 \mathrm{a}}, \mathrm{H}_{2 \mathrm{~b}}$, and $\mathrm{H}_{2 \mathrm{c}}$ are supported. While both attitudes influence people's intentions, positive attitudes are more influential in predicting people’s intentions to start a new physical activity (please see Table 2). Therefore the results support the TPB, especially in the context of volitional behaviours such as physical activity as our findings show that attitudes affect behavioural intentions. Interestingly, while positive attitudes have been able to predict behavioural intentions, our findings indicate that negative attitudes are also able to predict people's intentions (or lack thereof) to start a new physical activity for individuals who are healthy-weight and overweight but not for those who are obese (facilitating intentions to start a new physical activity). As previously mentioned, an 
individual evaluates all consequences, both negative and positive, attached to each of their beliefs (Godin, 1993) and it is the outcome of this evaluation that may be driving volitional behaviour. Contrary to exchange theory which suggests that benefits need to be promoted and barriers need to be minimised, the results of the current study indicate more understanding of the attitude interplay is needed to change individual volition to perform a behaviour.

Moreover, the findings show that instrumental attitudes are significant in predicting individuals' lack of intention to start a new physical activity for individuals who are overweight $(\beta=-0.148, p<0.05)$. Due to the opposite direction of the result, $\mathrm{H}_{3 \mathrm{~b}}$ is not supported. Furthermore, for individuals who are healthy-weight and obese, the results show that instrumental attitudes are not significant in predicting individuals' intention to start a new activity. Hence $\mathrm{H}_{3 \mathrm{a}}$ and $\mathrm{H}_{3 \mathrm{c}}$ are not supported.

The findings also show that affective attitudes are not significant in explaining individuals' intentions to start a new physical activity. Thus, $\mathrm{H}_{4 \mathrm{a}}, \mathrm{H}_{4 \mathrm{~b}}$ and $\mathrm{H}_{4 \mathrm{c}}$ are not supported. The findings suggest that knowing the benefits (instrumental) and emotional consequences (affective) did not influence people's intentions to start a new physical activity rather the combination of negative and positive dispositions towards physical activity were more influential on the intention to increase physical activity. The results of the current study indicate that inclusion of different attitude types to examine behavioural intentions may impact study outcomes. The findings of this study are in contrast to other studies which found that instrumental and affective beliefs play an important role in exercise behaviour motivation such as intention to go jogging and hiking (i.e. Valois et al. 1988; Godin, 1987). It is possible that by including more attitudinal types the role of instrumental and affective attitudes in influencing behavioural intentions is diminished. 
In the context of physical activity, consideration of the perceived benefits (positive attitudes) and barriers of physical activity (negative attitudes) may offer more insights for social marketers than instrumental or affective attitudes. The results of the current study suggest that instrumental and affective attitudes did not influence people's intentions to start a new physical activity, while both positive and negative attitudes positively influence people's intentions to start a new physical activity. While people know that exercise is good for them a communication focus on benefits and barriers of physical activity is likely to increase intentions and subsequent physical activity behaviour. The results of the current study are consistent with Lowe et al. (2002) who found that the benefits of exercise were not always translated into appropriate behaviour. Instrumental and affective attitudes exhibited no link with future intention to start a new physical activity.

Furthermore, Table 4 shows differences between various demographic groups, which provides further important insights to which particular groups the positive and negative attitudes towards physical activity comes from. Within BMI levels, people who are in the healthy-weight category exhibit a more positive attitude $(\mathrm{M}=3.82)$ towards physical activity than people who are in the overweight $(\mathrm{M}=3.72)$ and obese $(\mathrm{M}=3.63)$ categories. Further, people who are in the healthy-weight category exhibit a less negative attitude $(M=2.41)$ than people who are in the overweight $(\mathrm{M}=2.55)$ and obese $(\mathrm{M}=2.87)$ categories. In other words, healthy-weight people have higher positive attitudes and lower negative attitudes towards physical activity compared to those who are underweight, and significantly so compared to the overweight and obese. It can be suggested that healthier people understand the various challenges in performing physical activities such as tiredness, pain, sweating etc. along with 
the potential benefits of physical activities. In contrast, people who are overweight and obese perceive lower benefits and more barriers to physical activity, and thus are less willing to start a new activity. It is important to note that intentions to increase physical activity would be expected to be lower for respondents who are already taking on substantial amounts of activity. An examination of self-reported physical activity is provided to consider this issue. The results show obese people $(M=1.58)$ did less physical exercise than healthy-weight (M=1.93) and overweight people $(M=1.94)$ (see Table 5). Furthermore, obese people show less affective attitudes, which mean they perceive physical activity as more unpleasant and less enjoyable compared to people who are healthy-weight and overweight. Nonetheless, obese people report lower physical activity levels and higher intentions to start a new physical activity than overweight people.

Insert Table 4 \& 5 About Here

Post-hoc regression analyses provide further insights regarding which of the three groups (healthy-weight, overweight, obese) contribute to the strongest attitudes towards physical activity (please see Table 6). Table 6 suggests that people in both healthy-weight and overweight categories understand the value of physical activity (instrumental attitude), however, it is the healthy-weight group that seems to like physical activity but not the obese (affective attitude and positive attitude, though the latter are not significant). This is verified by the fact that people in the obese category have a negative attitude towards physical activity and people in the healthy-weight category do not.

Insert Table 6 About Here 
In regards to differences between genders, females report more positive attitudes and higher intentions to start a new physical activity than males. Furthermore, the results demonstrate that age does not influence people's attitudes and intentions. This is in contrast with Mc.Auley et al.’s (2003) study, where older individuals were less engaged in any regular physical activities compared to younger individuals. People with higher income $(>\$ 100,000)$ show a more positive attitude toward starting a new physical activity than people with lower income. Moreover, people with higher income also show higher intention to start a new physical activities compared to people with lower income. Finally, people with higher education (university or more) exhibit a more positive attitude and higher intention to start a new physical activity compared to people with lower education levels. This is consistent with Cerin and Leslie, (2008), Corti and Donovan, (2002) and Lindstron et al.’s (2001) studies where lower socio-economic status has been found to be associated with insufficient physical activity.

\section{Conclusions and implications for social marketing}

From a theoretical perspective, the results of our study provide further empirical support for using the TPB for volitional behaviours such as physical activity and indicate that consideration of four attitude types may enhance understanding of how to influence behavioural intentions. Our findings indicate that when individuals hold both high positive and lower negative attitudes toward physical activity they will have higher intentions to start a new physical activity. Of concern in terms of addressing the obesity epidemic may be the fact that the results of the current study identified that overweight and obese people have higher negative and less positive attitudes than healthier people. The results indicate that overcoming negative attitudes and reinforcing positive attitudes remains as a necessary condition to influence volitional behaviours such as starting a new physical activity, which 
requires an informed decision to join a sporting team, sign onto a gymnasium, etc. Further, the results of this research suggest that people with higher intentions to engage in new physical activities understand both positive and negative effects of physical activities, and they may engage in physical activities not only because of the process of physical activity, but also because of its outcome. In future research, reasons why people engage in new physical activities (e.g. goals) and their expectations towards outcomes should be considered to better understand behavioural intentions and subsequent physical activity behaviours.

Furthermore, the study shows that overweight people show less intention to exercise compared to obese people. It can be suggested that people who are overweight may not see themselves in a health-risk situation thus are unable to see the need for exercise. This is a gap that needs to be addressed by social marketers and can be explored in future research. Social marketing campaigns should first focus on raising the awareness of a healthy body weight, before fostering further behaviour change leading to healthier lifestyles with physical activity as it integral component (Hamilton \& White, 2008). Further, as females show more positive attitudes and higher intentions to start a new physical activity than males, the investment in social marketing programs targeting women may gain the highest and quickest return on investment. This study also indicates that it is equally important to acknowledge the socioeconomic aspects associated with engaging in a new physical activity. Social marketers should focus on individuals with lower socio-economic status, especially as they display less positive attitudes and willingness to start a new physical activity. This situation is further compounded as other studies show that people with lower education and income also have less healthy dietary habits (Leather \& Dowler, 1997; Lobstein, 1999). This study highlights the complexity of lifestyle factors such physical activity and diet which tend to deteriorate moving from higher to lower socio-economic class (Blaxter, 1997; Adler \& Ostrove, 1999). 
Finally, this study has several limitations. First, it is limited to a convenience, crosssectional sample that was comprised of one large city in Australia. Secondly, it is based on self-reported intentions which might limit the actual intentions and more importantly understanding the subsequent behaviours of these individuals. Therefore, future research is recommended that incorporates longitudinal data to examine the long-term effect of people’s attitudes toward physical activity on behavioural intentions and subsequent behaviour to empirically examine causality. Future research is recommended to empirically examine alternative models. One alternate model that warrants consideration is to use instrumental and affective attitudes as moderating variables and to include additional variables known to explain behavioural intentions such as perceived behavioural control and social norms (injunctive and descriptive norms).

The results of the current study indicate that inclusion of different attitude types to examine behavioural intentions may impact study outcomes. For example, the current study indicates instrumental and affective beliefs play an important role in intention to go jogging and hiking which contrasts with previous studies (i.e. Valois et al., 1988; Godin, 1987). Meta-analyses are recommended to gain a more complete understanding of the attitude and intention interplay.

Future research employing alternate methods, such as observational data, is also recommended to extend our understanding beyond both behavioural intentions and volitional behaviours; given that intentions do not always lead to subsequent behaviour (Holdershaw et al., 2011) and not all behaviours are volitional. As acknowledged by Wymer (2011), to further understand how to combat the increasing prevalence of sedentary lifestyle and the obesity epidemic in Australia and worldwide (ABS, 2011; Kemper, 1995; Troiani et al., 2008), social marketers need to move beyond the downstream, consumer-focused interventions and assumptions of individual voluntary behaviour to address the problem of 
overweight and obesity. Given that much behaviour is automatic, and that individuals may not always make an active and conscious decision in regards to such trivial behaviours as taking the stairs or elevator, it is important that research methods extend beyond self-report methods such as surveys to develop a more comprehensive view of physical activity behaviours, in particular behaviours that are involuntary. In addition, future studies should explore not only physical activities but also other health-related behaviours such as dietary patterns, drinking and smoking behaviours as these behaviours will have a significant impact on people's health. 


\section{Acknowledgements}

The Victorian Health Promotion Foundation (VicHealth) funded and supported this research. The funders played no role in study design, collection, analysis, interpretation of data, or in the decision to submit the paper for publication. They accept no responsibility for contents. The authors wish to acknowledge research assistance provided during the research design and data collection stages of this project.

\section{References}

Aarts, H., Paulussen, T., Schaalma, H., 1997. Physical exercise habit: on the conceptualization and formation of habitual health behaviours. Health Education Research 12(3): 363-374.

Abraham, C., Sheeran, P. 2000. Understanding and changing health behaviour: From health beliefs to self-regulation. In P. Norman, C. Abraham, \& M. Conner (Eds.), Understanding and changing health behaviour (pp. 3-24). Amsterdam: Harwood.

Adler, N.E. and Ostrove, J.M. 1999. Socioeconomic Status and Health: What We Know and What We Don't. Annals of the New York Academy of Sciences 896: 3-15.

Ajzen, I. 1989. Attitude structure and behavior. In A. R. Pratkanis, S. J. Beckler, \& A. G. Greenwald (Eds.), Attitude structure and function (pp. 241-274). Hillsdale, NJ: Lawrence Erlbaum.

Ajzen, I., 1991. The theory of planned behavior. Organizational Behavior and Human Decision Processes 50(2): 179-211.

Ajzen, I., Fishbein, M., 1980. Understanding attitudes and predicting social behaviour. Prentice-Hall, Englewood Cliffs NJ.

Ajzen, I., Driver, B. L., 1992. Application of the theory of planned behavior to leisure choice. Journal of Leisure Research 24: 207-224.

Armitage, C. J., Conner, M., 2001. Efficacy of the theory of planned behaviour: A metaanalytic review. British Journal of Social Psychology 40(4): 471-499.

Australian Bureau of Statistics, 2011. Physical activity in Australia: A snapshot, 2007-2008. http://www.abs.gov.au/ausstats/abs@.nsf/mf/4835.0.55.001/ [accessed 25 November 2013].

Australian Sports Commission, 2010. The Exercise, Recreation and Sport Survey (ERASS). http://www.ausport.gov.au/information/casro/ERASS [accessed 26 August 2014].

Blair, S. N., Cheng, Y., Holder, J. S., 2001. Is physical activity or physical fitness more important in defining health benefits?. Medicine and Science in Sports and Exercise 33 (6) (SUPP): S379-S399.

Blaxter M., 1987. Evidence of inequality in health from a national survey. Lancet 2(8549): 30-33.

Cerin, E., Leslie, E. 2008. How socio-economic status contributes to participation in leisure-time physical activity. Social science \& medicine 66(12): 2596-2609.

Conger, A. J. 1974. A revised definition for suppressor variables: A guide to their identification and interpretation. Educational and Psychological Measurement 34: 3546.

Conner, M., Sparks, P. 1996. The theory of planned behaviour and health behaviours. In M. Conner \& P. Sparks (Eds.), Predicting health behavior: Research and practice with social cognition models. (pp 121-162). Buckingham, England: Open University Press.

Conner, M., Sparks, P., 2005. Theory of planned behaviour and health behaviour. Predicting 
Health Behaviour 2: 170-222.

Courneya, K. S., 1995. Understanding readiness for regular physical activity in older individuals: an application of the theory of planned behaviour. Health Psychology 14 (1): 80.

Courneya, K. S., Nigg, C. R., Estabrooks, P. A., 1998. Relationships among the theory of planned behavior, stages of change, and exercise behavior in older persons over a three year period. Psychology and Health 13(2): 355-367.

Courneya, K. S., Bobick, T. M., Schinke, R. J.,1999. Does the theory of planned behavior mediate the relation between personality and exercise behavior? Basic and Applied Social Psychology 21(4): 317-324.

Deforche, B. I., De Bourdeaudhuij, I. M., Tanghe, A. P. 2006. Attitude toward physical activity in normal-weight, overweight and obese adolescents. Journal of Adolescent Health 38(5): 560-568.

Dishman, R. K., Buckworth, J. 2001. Exercise psychology. Champaign, IL: Human Kinetics

Dwyer, T.,Blizzard, L., Dean, K. 1996. Physical activity and performance in children. NutritionalReviews 54: S27-31.

Fishbein, M., Ajzen, I., 1975. Belief, attitude, intention and behavior: An introduction to theory and research. Addison-Wesley, Reading MA.

Furr, M. 2011. Scale construction and psychometrics for social and personality psychology. SAGE Publications Ltd.

Giles-Corti, B., Donovan, R. J. 2002. Socioeconomic status differences in recreational physical activity levels and real and perceived access to a supportive physical environment. Preventive Medicine 35(6): 601-611.

Godin, G., 1993. The theories of reasoned action and planned behavior: Overview of findings, emerging research problems and usefulness for exercise promotion. Journal of Applied Sport Psychology 5(2): 141-157.

Godin, G., Kok, G., 1996. The theory of planned behavior: a review of its applications to health-related behaviors. American Journal of Health Promotion 11(2): 87-98.

Godin, G., 1987. Importance of the emotional aspect of attitude to predict intention. Psychological Report 61: 719-723

Godin, G., Valois, P., Lepage, L., 1993. The pattern of influence of perceived behavioral control upon exercising behavior: An application of Ajzen's theory of planned behaviour. Journal of Behavioral Medicine 16(1): 81-102.

Hair J.F., Anderson, R.E., Tatham, R.L. Black, W.C. 1998. Multivariate Data Analysis. Pearson Education. Upper Saddle River, NJ, 07458.

Hamilton, K., White, K. M. 2008. Extending the theory of planned behavior: the role of self and social influences in predicting adolescent regular moderate-to-vigorous physical activity. Journal of Sport \& Exercise Psychology 30(1): 56-74

Hinkle, D. E., Wiersma, W. Jurs, S. G. 1994. Applied statistics for the behavioral sciences (3rd ed.). Boston: Houghton Mifflin.

Holdershaw, J., Gendall, P., Wright, M. 2003. Predicting willingness to donate blood. Australasian Marketing Journal 11(1): 87-96.

Holdershaw, J., Gendall, P., Wright, M. 2011. Predicting blood donation behaviour: further application of the theory of planned behaviour. Journal of Social Marketing 1(2): 120132.

Kemper, H. C. 1995. The Amsterdam Growth Study: A longitudinal analysis of health, fitness, and lifestyle, 42-44. Human Kinetics, Champaign IL.

Leather S, Dowler, E., 1997. Intake of micronutrients in Britain's poorest fifth has declined. British Management Journal 314: 1412-1413. 
Lindström, M., Hanson, B. S., \& Östergren, P. O. 2001. Socioeconomic differences in leisure-time physical activity: the role of social participation and social capital in shaping health related behaviour. Social science \& medicine 52(3): 441-451.

Lobstein, T. 1999. Health, income and diet. In: Cottee, P. (ed.) Tackling Inequalities in Health and Diet Related Disease, pp 3-10. Sustain Publ., KKS Printing, London.

Lowe, R., Eves, F., Carroll, D. 2002. The influence of affective and instrumental beliefs on exercise intentions and behavior: A longitudinal analysis. Journal of Applied Social Psychology 32(6): 1241-1252.

Luca, N. R., Suggs, S. 2013. Theory and model use in social marketing interventions. Journal of Health Communications 18(1): 20-40.

McAuley, E., Jerome, G. J., Elavsky, S., Marquez, D. X., \& Ramsey, S. N. 2003. Predicting long-term maintenance of physical activity in older adults. Preventive Medicine 37(2): 110-118.

Montano, D. E., Kasprzyk, D. 2008. Theory of reasoned action, theory of planned behavior, and the integrated behavioral model. Health behavior and health education: Theory, research, and practice 4: 67-95.

Nelson, T. D., Benson, E. R., Jensen, C. D. 2010. Negative attitudes toward physical activity: Measurement and role in predicting physical activity levels among preadolescents. Journal of Pediatric Psychology 35(1): 89-98.

Mummery, W. K., Spence, J. C., Hudec, J. C. 2000. Understanding physical activity intention in Canadian school children and youth: an application of the theory of planned behavior. Research Quarterly for Exercise and Sport 71(2): 116-124.

Orbell, S., Sheeran, P. 1998. Inclined abstainers: A problem for predicting health -related behaviour. British Journal of Social Psychology 37: 151-165.

Parkinson, J., Russell-Bennett, R., Previte, J., 2012. Mum or bub? Which influences breastfeeding loyalty. Australasian Marketing Journal 20(1): 16-23.

Pedhazur, E. J. 1982. Multiple regression in behavioral research: Explanation and prediction (2nd ed.). New York: Holt, Rinehart and Winston.

Sallis, J. F., Patrick, K., 1994. Physical activity guidelines for adolescents: consensus statement. Pediatric Exercise Science 6: 302-302.

Shephard,R.J. 1996. Habitual physical activity and academic performance. Nutrition Reviews 54: S32-36.

Smith, S., Paladino, A. 2010. Eating clean and green? Investigating consumer motivations towards the purchase of organic food. Australasian Marketing Journal 18(2): 93-104.

Sniehotta, F. F., Scholz, U., Schwarzer, R. 2005. Bridging the intention-behaviour gap: Planning, self-efficacy, and action control in the adoption and maintenance of physical exercise. Psychology \& Health 20(2): 143-160.

Storch, E. A., Milsom, V. A., DeBraganza, N., Lewin, A. B., Geffken, G. R., Silverstein, J. H., 2007. Peer victimization, psychosocial adjustment, and physical activity in overweight and at-risk-for-overweight youth. Journal of Pediatric Psychology 32(1): 80-89.

Talbot, L. A., Metter, E. J., Fleg, J. L. 2000. Leisure-time physical activities and their relationship to cardiorespiratory fitness in healthy men and women 18-95 years old. Medicine and science in sports and exercise 32(2): 417-425.

Troiani, V., Peelle, J. E., Clark, R., Grossman, M., 2009. Is it logical to count on quantifiers? Dissociable neural networks underlying numerical and logical quantifiers. Neuropsychologia 47(1): 104-111.

Valois, P., Desharnais, R., Godin, G. 1988. A comparison of the Fishbein and Ajzen and the Triandis attitudinal models for the prediction of exercise intention and behaviour. Journal of Behavioral Medicine 11(5): 459-472. 
Vidmar, P. 1992. The role of the federal government in promoting health through the schools: report from the President's Council on Physical Fitness and Sports. Journal of School Health 62: 129-130.

Wallston, K., Armstrong, C. 2002. Theoretically-based strategies for health behaviour change. In M. P. O’Donnell (Ed.), Health promotion in the workplace(3rd Edn., pp. 182-201). Albany, NY: Delmar.

Weinstein, N. D. 2003. Exploring the links between risk perceptions and preventive health behavior. In J. Suls, \& K. Wallston (Eds.), Social psychological foundations of health and illness (pp. 22-53). Oxford, England: Blackwell.

Wolley, K.K. 1997. How Variables Uncorrelated with the Dependent Variable Can Actually Make Excellent Predictors: The Important Suppressor Variable Case. http://ericae.net/ft/tamu/supres.htm [accessed 3 July 2014].

Wymer, W. 2011. Developing more effective social marketing strategies. Journal of Social Marketing 1(1): 17-31. 


\section{Appendix}

Table 1. Scale items, origin in the literature and scale anchors

\begin{tabular}{|c|c|}
\hline Attitude (Negative) (Nelson et al., 2010) & Scale Anchors \\
\hline If I were to be physically active on most day & \multirow[t]{9}{*}{$-3=$ strongly disagree; $3=$ strongly agree } \\
\hline ...it would be painful & \\
\hline ...it would be difficult & \\
\hline ...it would be embarrassing. & \\
\hline ...it would make me feel uncomfortable & \\
\hline ...it would make me tired & \\
\hline ...it would make me sore & \\
\hline ...it would be a hassle & \\
\hline ...it would take too much time & \\
\hline \multicolumn{2}{|l|}{ Attitude (Positive) (Nelson et al., 2010) } \\
\hline If I were to be physically active on most day & \multirow[t]{7}{*}{-3=strongly disagree; $3=$ strongly agree } \\
\hline ...it would help me cope with stress & \\
\hline ...it would help me make new friends & \\
\hline ...it would get or keep me in shape & \\
\hline ...it would help make me more attractive & \\
\hline ...it would give me more energy & \\
\hline ...it would make me better in sports, dance and other activities & \\
\hline \multicolumn{2}{|l|}{ Attitude (Instrumental) (Conner and Sparks, 1996) } \\
\hline Exercise is... & -3=harmful; 3=beneficial \\
\hline Exercise is... & $-3=$ bad; 3=good \\
\hline Exercise is... & -3=worthless; 3=valuable \\
\hline \multicolumn{2}{|l|}{ Attitude (Affective) (Conner and Sparks, 1996) } \\
\hline Exercise is... & -3=unpleasant; 3=beneficial \\
\hline Exercise is... & -3=unenjoyable; 3=enjoyable \\
\hline \multicolumn{2}{|l|}{ Intention (Fishbein and Ajzen, 1975) } \\
\hline I intend to start a new physical activity in the next 12 months & \multirow[t]{3}{*}{-3=extremely unlikely; 3 extremely likely } \\
\hline I will try to start a new physical activity in the next 12 months & \\
\hline I plan to start a new physical activity in the next 12 months & \\
\hline
\end{tabular}


Table 2. Correlation matrix for attitudes and intentions to start a new physical activity

\begin{tabular}{|c|c|c|c|c|c|}
\hline $\begin{array}{l}\text { Construct (Healthy- } \\
\text { Weight) }\end{array}$ & $\begin{array}{l}\text { Attitude } \\
\text { (Negative) }\end{array}$ & $\begin{array}{l}\text { Attitude } \\
\text { (Positive) }\end{array}$ & $\begin{array}{l}\text { Attitude } \\
\text { (Instrumental) }\end{array}$ & $\begin{array}{l}\text { Attitude } \\
\text { (Affective) }\end{array}$ & Intention \\
\hline 1. Attitude (Negative) & 1 & & & & \\
\hline 2. Attitude (Positive) & $-0.238 * *$ & 1 & & & \\
\hline 3. Attitude (Instrumental) & $-0.135 * *$ & $0.109 *$ & 1 & & \\
\hline 4. Attitude (Affective) & $-0.245^{* *}$ & $0.154^{* *}$ & $0.791^{* *}$ & 1 & \\
\hline 5. Intention & 0.048 & $0.333^{* *}$ & -0.046 & -0.022 & 1 \\
\hline $\begin{array}{l}\text { Construct (Overweight) } \\
\mathrm{N}=427\end{array}$ & $\begin{array}{l}\text { Attitude } \\
\text { (Negative) }\end{array}$ & $\begin{array}{l}\text { Attitude } \\
\text { (Positive) }\end{array}$ & $\begin{array}{l}\text { Attitude } \\
\text { (Instrumental) }\end{array}$ & $\begin{array}{l}\text { Attitude } \\
\text { (Affective) }\end{array}$ & Intention \\
\hline 1. Attitude (Negative) & 1 & & & & \\
\hline 2. Attitude (Positive) & -0.327 & 1 & & & \\
\hline 3. Attitude (Instrumental) & $-0.122 *$ & $0.248^{* *}$ & 1 & & \\
\hline 4. Attitude (Affective) & $-0.397 * *$ & $0.321^{* *}$ & $0.725^{* *}$ & 1 & \\
\hline 5. Intention & -0.028 & $0.404^{* *}$ & 0.037 & 0.091 & 1 \\
\hline $\begin{array}{l}\text { Construct (Obese) } \\
\mathrm{N}=334\end{array}$ & $\begin{array}{l}\text { Attitude } \\
\text { (Negative) }\end{array}$ & $\begin{array}{l}\text { Attitude } \\
\text { (Positive) }\end{array}$ & $\begin{array}{l}\text { Attitude } \\
\text { (Instrumental) }\end{array}$ & $\begin{array}{l}\text { Attitude } \\
\text { (Affective) }\end{array}$ & Intention \\
\hline 1. Attitude (Negative) & 1 & & & & \\
\hline 2. Attitude (Positive) & $-0.276^{* *}$ & 1 & & & \\
\hline 3. Attitude (Instrumental) & $-0.275^{* *}$ & $0.303^{* *}$ & 1 & & \\
\hline 4. Attitude (Affective) & $-0.470 * *$ & $0.298^{* *}$ & $0.617^{* *}$ & 1 & \\
\hline 5. Intention & -0.043 & $0.380^{* *}$ & 0.051 & -0.021 & 1 \\
\hline
\end{tabular}

$* p<0.01 .{ }^{* *} p<0.005$ 
Table 3. Regression analysis for attitudes on the intentions to start a new physical activity

\begin{tabular}{|c|c|c|c|}
\hline Model (Healthy-Weight) & Standardized beta & t-value & Significant \\
\hline \multicolumn{2}{|c|}{ Dependent variable: Intention to start a new physical activity } & -6.687 & 0.000 \\
\hline Attitude (Negative) & 0.145 & 2.847 & 0.005 \\
\hline Attitude (Positive) & 0.373 & 7.541 & 0.000 \\
\hline Attitude (Instrumental) & -0.082 & -1.031 & 0.303 \\
\hline Attitude (Affective) & 0.031 & 0.378 & 0.705 \\
\hline $\mathrm{R}^{2}=0.137$ & F-value $=14.968$ & & \\
\hline Adjusted $\mathrm{R}^{2}=0.128$ & Significance $=\mathbf{0 . 0 0 0}$ & & \\
\hline Model (Overweight) & Standardized beta & t-value & Significant \\
\hline \multicolumn{2}{|c|}{ Dependent variable: Intention to start a new physical activity } & -7.436 & 0.000 \\
\hline Attitude (Negative) & 0.151 & 2.676 & 0.008 \\
\hline Attitude (Positive) & 0.455 & 8.537 & 0.000 \\
\hline Attitude (Instrumental) & -0.148 & -2.062 & 0.040 \\
\hline Attitude (Affective) & 0.119 & 1.532 & 0.126 \\
\hline $\mathrm{R}^{2}=0.188$ & F-value $=19.809$ & & \\
\hline Adjusted $\mathrm{R}^{2}=0.179$ & Significance $=\mathbf{0 . 0 0 0}$ & & \\
\hline Model (Obese) & Standardized beta & t-value & Significant \\
\hline \multicolumn{2}{|c|}{ Dependent variable: Intention to start a new physical activity } & -3.908 & 0.000 \\
\hline Attitude (Negative) & 0.015 & 0.223 & 0.824 \\
\hline Attitude (Positive) & 0.375 & 6.056 & 0.000 \\
\hline Attitude (Instrumental) & 0.043 & 0.601 & 0.549 \\
\hline Attitude (Affective) & -0.130 & -1.680 & 0.094 \\
\hline $\mathrm{R}^{2}=0.132$ & F-value $=10.151$ & & \\
\hline Adjusted $\mathrm{R}^{2}=0.119$ & Significance $=\mathbf{0 . 0 0 0}$ & & \\
\hline
\end{tabular}

${ }^{*} p<0.01 .{ }^{* *} p<0.005$ 
Table 4. ANOVA Between Groups (Attitude)

\begin{tabular}{|c|c|c|c|c|c|}
\hline \multirow[t]{2}{*}{ Demographic } & \multicolumn{4}{|c|}{ Attitude } & \multirow[t]{2}{*}{ Intention } \\
\hline & Negative & Positive & Instrumental & Affective & \\
\hline BMI (F-value/ sig) & $35.54 / 0.00$ & $9.14 / \mathbf{0 . 0 0}$ & $1.50 / 0.22$ & $21.56 / \mathbf{0 . 0 0}$ & $\mathrm{F}=8.59 / \mathbf{0 . 0 0}$ \\
\hline Healthy-Weight (a)(37.6\% & 2.41 & 3.82 & 2.04 & 1.68 & 0.34 \\
\hline Overweight (b)(35\%) & 2.55 & 3.72 & 2.05 & 1.46 & 0.07 \\
\hline \multirow[t]{2}{*}{ Obese $(c)(27.4 \%)$} & 2.87 & 3.63 & 1.86 & 0.88 & 0.63 \\
\hline & $\begin{array}{l}\text { Note: } \\
\text { (a) is sig. } \\
\text { different } \\
\text { than (b) \& } \\
\text { (c); (b) is sig } \\
\text { different } \\
\text { than (c) }\end{array}$ & $\begin{array}{l}\text { Note: } \\
\text { (a) is sig. } \\
\text { different than } \\
\text { (b) \& (c) }\end{array}$ & $\begin{array}{l}\text { Note: } \\
\text { no sig. difference }\end{array}$ & $\begin{array}{l}\text { Note: } \\
\text { (c) is sig } \\
\text { different } \\
\text { than (a) \& } \\
\text { (b) }\end{array}$ & $\begin{array}{l}\text { Note: } \\
\text { (b) is sig } \\
\text { different } \\
\text { than (c) }\end{array}$ \\
\hline Gender (F-value/ sig) & $3.62 / 0.70$ & $0.04 / \mathbf{0 . 0 0}$ & $3.02 / 0.13$ & $1.01 / 0.87$ & $0.02 / \mathbf{0 . 0 0}$ \\
\hline Female(62.1\%) & 2.58 & 3.86 & 2.01 & 1.38 & 0.56 \\
\hline Male(37.9\%) & 2.57 & 2.61 & 1.87 & 1.36 & -0.08 \\
\hline Age (F-value/ sig) & $0.85 / 0.51$ & $0.51 / 0.76$ & $0.53 / 0.74$ & $0.39 / 0.74$ & $0.76 / 0.57$ \\
\hline $18-24(a)(1.7 \%)$ & 2.27 & 3.89 & 1.64 & 1.27 & 0.08 \\
\hline $25-34(b)(12.7 \%$ & 2.62 & 3.76 & 1.95 & 1.27 & 0.28 \\
\hline $35-44$ (c)(15.6\%) & 2.57 & 3.73 & 1.90 & 1.31 & 0.48 \\
\hline $45-54(d)(21.9 \%)$ & 2.60 & 3.77 & 1.91 & 1.34 & 0.41 \\
\hline $55-64(e)(22.2 \%)$ & 2.56 & 3.72 & 2.00 & 1.47 & 0.33 \\
\hline \multirow[t]{2}{*}{65 and above $(f)(26 \%)$} & 2.60 & 3.73 & 2.06 & 1.42 & 0.20 \\
\hline & $\begin{array}{l}\text { Note: } \\
\text { no sig diff. }\end{array}$ & $\begin{array}{l}\text { Note: } \\
\text { no sig diff. }\end{array}$ & $\begin{array}{l}\text { Note: } \\
\text { no sig diff. }\end{array}$ & $\begin{array}{l}\text { Note: } \\
\text { no sig diff. }\end{array}$ & $\begin{array}{l}\text { Note: } \\
\text { no sig diff. }\end{array}$ \\
\hline Income (F-value/ sig) & $2.16 / 0.06$ & $9.23 / \mathbf{0 . 0 0}$ & $0.82 / 0.53$ & $0.60 / 0.70$ & $5.53 / \mathbf{0 . 0 0}$ \\
\hline$<\$ 20,000(a)(9.8 \%)$ & 2.76 & 3.55 & 1.84 & 1.36 & -0.05 \\
\hline$\$ 21-\$ 39,999(b)(18.7 \%)$ & 2.65 & 3.58 & 1.85 & 1.21 & -0.12 \\
\hline$\$ 40-\$ 59,999(c)(19.1 \%)$ & 2.60 & 3.71 & 2.09 & 1.48 & 0.36 \\
\hline$\$ 60-\$ 79,999(d)(15.7 \%)$ & 2.54 & 3.80 & 1.91 & 1.43 & 0.58 \\
\hline$\$ 80-\$ 99,999(e)(12.7 \%)$ & 2.53 & 3.78 & 1.97 & 1.42 & 0.44 \\
\hline \multirow[t]{2}{*}{$\$ 100<(f)(24.1 \%)$} & 2.51 & 3.89 & 2.05 & 1.41 & 0.55 \\
\hline & $\begin{array}{l}\text { Note: } \\
\text { no sig diff. }\end{array}$ & $\begin{array}{l}\text { Note: } \\
\text { - (f) is sig } \\
\text { different than } \\
\text { (a), (b) \& (c). } \\
\text { - (e) is sig } \\
\text { different than } \\
\text { (a) \& (b) }\end{array}$ & $\begin{array}{l}\text { Note: } \\
\text { no sig different }\end{array}$ & $\begin{array}{l}\text { Note: } \\
\text { no sig } \\
\text { different }\end{array}$ & $\begin{array}{l}\text { Note: } \\
\text { (a) is sig } \\
\text { different } \\
\text { than (d) \& } \\
\text { (f) } \\
\text { (b) is sig } \\
\text { different } \\
\text { than (d), (e) } \\
\text { \& (f) }\end{array}$ \\
\hline $\begin{array}{l}\text { Education } \\
\text { (F-value/ sig) }\end{array}$ & $1.04 / 0.37$ & $3.14 / 0.02$ & $0.48 / 0.69$ & $0.15 / 0.92$ & $3.65 / 0.01$ \\
\hline University or higher (a)(45.8\%) & 2.54 & 3.78 & 1.94 & 1.36 & 0.39 \\
\hline TAFE / Diploma (b)(25.4\%) & 2.62 & 3.72 & 2.03 & 1.43 & 0.46 \\
\hline Completed HS (c)(14.6\%) & 2.63 & 3.69 & 1.87 & 1.33 & 0.23 \\
\hline \multirow[t]{2}{*}{ Some HS or lower $(d)(14.2 \%)$} & 2.56 & 3.63 & 2.01 & 1.34 & -0.05 \\
\hline & $\begin{array}{l}\text { Note: } \\
\text { no sig diff. }\end{array}$ & $\begin{array}{l}\text { Note: } \\
\text { (a) is sig } \\
\text { different than } \\
\text { (d) }\end{array}$ & $\begin{array}{l}\text { Note: } \\
\text { no sig diff. }\end{array}$ & $\begin{array}{l}\text { Note: } \\
\text { no sig diff. }\end{array}$ & $\begin{array}{l}\text { Note: } \\
\text { (a) is sig } \\
\text { different } \\
\text { than (d) }\end{array}$ \\
\hline
\end{tabular}


Table 5. ANOVA Between Groups (physical exercise)

\begin{tabular}{|c|c|c|c|c|c|c|}
\hline & \multicolumn{3}{|c|}{ Group (Mean) } & \multirow[t]{2}{*}{$\mathbf{F}$} & \multirow[t]{2}{*}{ Sig } & \multirow{2}{*}{$\begin{array}{l}\text { Note: at } \mathrm{p}< \\
0 / 05\end{array}$} \\
\hline & $\begin{array}{l}\text { Healthy- } \\
\text { weight (a) }\end{array}$ & Overweight (b) & Obese (c) & & & \\
\hline Physical Exercise & 1.93 & 1.94 & 1.58 & 17.72 & 0.00 & $\begin{array}{l}\text { (c) is } \\
\text { significantly } \\
\text { different than (a) } \\
\text { and (b) }\end{array}$ \\
\hline
\end{tabular}

Note: $0=$ no physical exercise ( 0 session/ week); $1=$ low physical exercise (1-2 sessions/ week); $2=$ medium physical exercise (3-5 sessions/ week; 3=high physical exercise (6 sessions/ week).

Table 6. Post-hoc regression analyses for attitudes on the intention to start a new physical activity.

\begin{tabular}{|l|l|l|l|}
\hline Model 1 & Standardized beta & t-value & Significant \\
\hline Dependent variable: Negative attitude & -0.130 & 40.879 & $\mathbf{0 . 0 0 0}$ \\
\hline Healthy-weight & -0.024 & -2.215 & $\mathbf{0 . 0 0 4}$ \\
\hline Overweight & 0.157 & -0.532 & 0.595 \\
\hline Obese & F-value $=24.895$ & 3.591 & $\mathbf{0 . 0 0 0}$ \\
\hline $\mathrm{R}^{2}=.059$ & Significance $=\mathbf{0 . 0 0 0}$ & & \\
\hline Adjusted $\mathrm{R}^{2}=.056$ & Standardized beta & t-value & \\
\hline Model $\mathbf{2}$ & & 72.582 & Significant \\
\hline Dependent variable: Positive attitude & 0.081 & 1.778 & $\mathbf{0 . 0 0 0}$ \\
\hline Healthy-weight & -0.003 & -0.065 & 0.076 \\
\hline Overweight & -0.063 & -1.438 & 0.948 \\
\hline Obese & F-value $=6.185$ & & 0.151 \\
\hline $\mathrm{R}^{2}=.015$ & Significance $=\mathbf{0 . 0 0 0}$ & & \\
\hline Adjusted $\mathrm{R}^{2}=.012$ & Standardized beta & t-value & \\
\hline Model $\mathbf{3}$ & & 12.488 & Significant \\
\hline Dependent variable: Instrumental attitude & 0.120 & 2.853 & $\mathbf{0 . 0 0 0}$ \\
\hline Healthy-weight & 0.118 & 2.600 & $\mathbf{0 . 0 0 8}$ \\
\hline Overweight & 0.058 & 1.338 & $\mathbf{0 . 0 0 9}$ \\
\hline Obese & F-value $=3.148$ & & 0.181 \\
\hline $\mathrm{R}^{2}=.008$ & Significance $=\mathbf{0 . 0 2 4}$ & & $\mathbf{0 . 0 0 0}$ \\
\hline Adjusted $\mathrm{R}^{2}=.005$ & Standardized beta & $\mathbf{t}$-value \\
\hline Model $\mathbf{4}$ & & 9.465 & $\mathbf{0 . 0 1 0}$ \\
\hline Dependent variable: Affective attitude & 0.111 & 2.498 & \\
\hline Healthy-weight & 0.043 & 0.758 & \\
\hline Overweight & -0.110 & -2.571 & \\
\hline Obese & F-value $=15.110$ & & \\
\hline $\mathrm{R}^{2}=.035$ & Significance $=\mathbf{0 . 0 0 0}$ & & \\
\hline Adjusted $\mathrm{R}^{2}=.033$ & & & \\
\hline & & & \\
\hline
\end{tabular}


--- END OF MANUSCRIPT --- 